\title{
Assessment of a Dynamic Watershed via Field Studies and GIS-Based Erosion Model
}

\author{
William M. C. Whitman ${ }^{1}$, Shahram Khosrowpanah ${ }^{2}$, Mark A. Lander ${ }^{1}$, Ujwalkumar D. Patil ${ }^{2,}$, \\ Joseph D. Rouse ${ }^{1}$
}

${ }^{1}$ Water and Environmental Research Institute, University of Guam, Mangilao, Guam

${ }^{2}$ School of Engineering, University of Guam, Mangilao, Guam

Email address:

patilu@ triton.uog.edu (U. D. Patil)

*Corresponding author

\section{To cite this article:}

William M. C. Whitman, Shahram Khosrowpanah, Mark A. Lander, Ujwalkumar D. Patil, Joseph D. Rouse. Assessment of a Dynamic Watershed via Field Studies and GIS-Based Erosion Model. Hydrology. Vol. 6, No. 3, 2018, pp. 88-99. doi: 10.11648/j.hyd.20180603.12

Received: November 20, 2018; Accepted: December 3, 2018; Published: December 26, 2018

\begin{abstract}
This paper presents a one-year-long study of the baseline hydrologic conditions of the Geus Watershed in the tropical island of Guam, through field observations. Data analyses show a strong correlation between stream level, turbidity, and rainfall within the watershed, suggesting a highly dynamic nature of Geus watershed. Field data were then used to create a stage discharge curve, which increases the efficiency of future watershed management by providing an estimate of stream flow from a simple measure of water level. The supplemental analyses based on the test results of soil samples and a GIS-based erosion model identified areas within the watershed with higher contributions to erosion potential. In addition, synthesis of the information in this watershed study will allow for future recommendations for effective and sustainable watershed management strategies, thereby opening a way for evaluating progress within the Geus watershed with continued monitoring.
\end{abstract}

Keywords: Watershed, GIS-Based Erosion Model, Turbidity, Stage Discharge Curve

\section{Introduction}

Erosion is a process by which soil particles are detached, transported, and deposited elsewhere by erosive agents such as wind or water. The process of erosion degrades the quality of the topsoil and the welfare of both freshwater and marine ecosystems, thus making it one of the most critical environmental issues affecting the island ecosystem. Guam being a tropical island receives heavy rainfall with mean annual, varying between $81^{\prime \prime}-110^{\prime \prime}$. In addition, the topography of southern Guam is mountainous and hence highly susceptible to erosion from human activities and other forms of environmental degradation [1-2], thereby making its habitat increasingly unsustainable.

The problems associated with erosion and sedimentation on Guam are almost exclusive to the southern volcanic region. Erosion runoff contributes to non-point sources of pollution, such as nutrients, pesticides, or sediment deposits. This affects the water quality of freshwater resources and ecosystems [3] as well as near-shore marine habitats [4-5] which provide important natural and economic benefits to Guam.

Most of previous studies concerning aspects of erosion in southern Guam watersheds quantified soil loss rates on relatively large scales, such as ton/hectare/week [6] or ton/acre/year [7-9]. This is useful for understanding longterm soil loss and for assessing the accuracy of erosion model estimates based on the RUSLE [1, 8, 10-12]. However, it masks the impacts of sediment plume dynamics and patterns of high-volume sediment loading characteristic of flash-flood conditions common on Guam. The recent UN report indicates that Europe loses about 970 million tons of soil every year due to erosion on account of poor land management practices and this estimate has reached to about 24 billion tons of soil loss throughout the world [13]. Thus, there is a growing need for studies that could assist us in providing better watershed management practices.

An empirical understanding of high-volume sediment loading over shorter, heavy rainfall events is better assessed 
by analyzing suspended solid concentrations over shorter durations. As a result, previous studies that correlated levels of turbidity, rainfall, and other hydrological factors in different watersheds of southern Guam were reviewed for this study $[12,14]$.

The main focus of this study is Geus watershed in Guam which is valuable as a natural resource to the coastal community of Merizo-village and hence, has been designated as a habitat Focus Area (Since, January 2014) by the National Oceanic and Atmospheric Administration (NOAA). As a Habitat Focus Area more resources are dedicated to the development and implementation of watershed management plans and conservation actions: This being the chief motivation for choosing Geus watershed for present studies.

The Geus Watershed is one of the smaller watersheds in southern Guam. It has one major river, the Geus River, with several upland tributaries surrounded by high slopes. It is one of three watersheds located in the southernmost village of Merizo, and is situated between the high peaks of Mt. Shroeder, Mt. Finansanta, and Mt. Sasalaguan (Figure 1). It also is bordered by Cocos Lagoon along the coast, with the Geus River discharging directly into the interior portion of the lagoon.

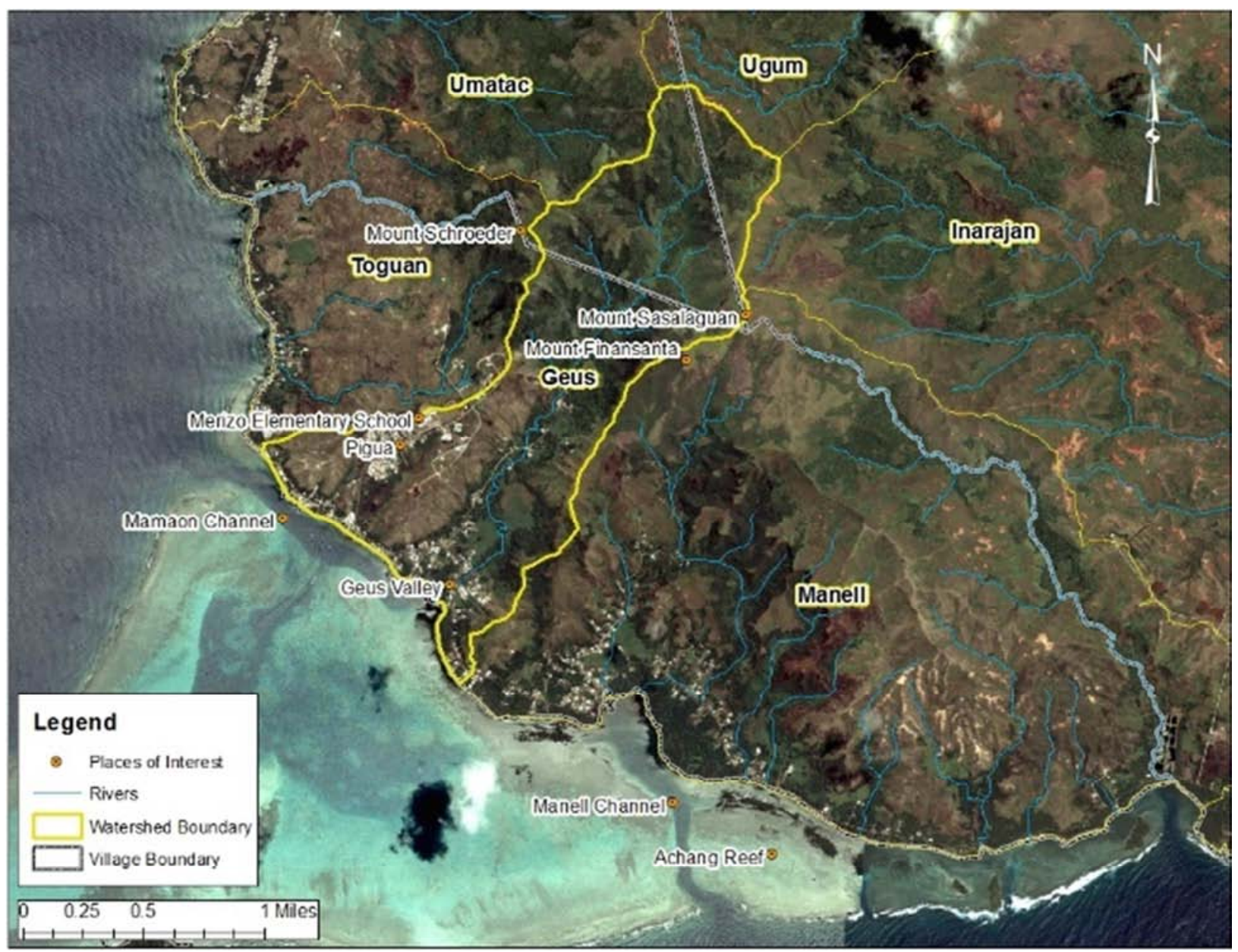

Figure 1. Geus watershed location in the village of Merizo in southern Guam.

The average annual rainfall over the Geus watershed varies between $95^{\prime \prime}-110^{\prime \prime}$ [15].

The goals of this research were accomplished in three phases. First, a watershed assessment was completed using all available physical and environmental information. Second, hydrologic data and soil samples were collected in the field to quantify and correlate baseline environmental conditions. Finally, all the data collected was analyzed and compared with data from similar studies that have occurred at other watersheds in southern Guam. The goal includes recommendations for watershed management strategies to help address issues with sedimentation on land and in nearshore communities.

\section{Methods}

\subsection{Field Observations}

Field visitations were conducted on a weekly basis from December 2013 through January 2015. During each visit, potential elements that may contribute to erosion and sedimentation that were observed were documented. These include vegetation types, Badland locations, slope and topography, and fires or other human activities (Figures 9 and 10). In addition, aerial surveys were conducted to observe land coverage and identify areas with more potential 
susceptibility to erosion.

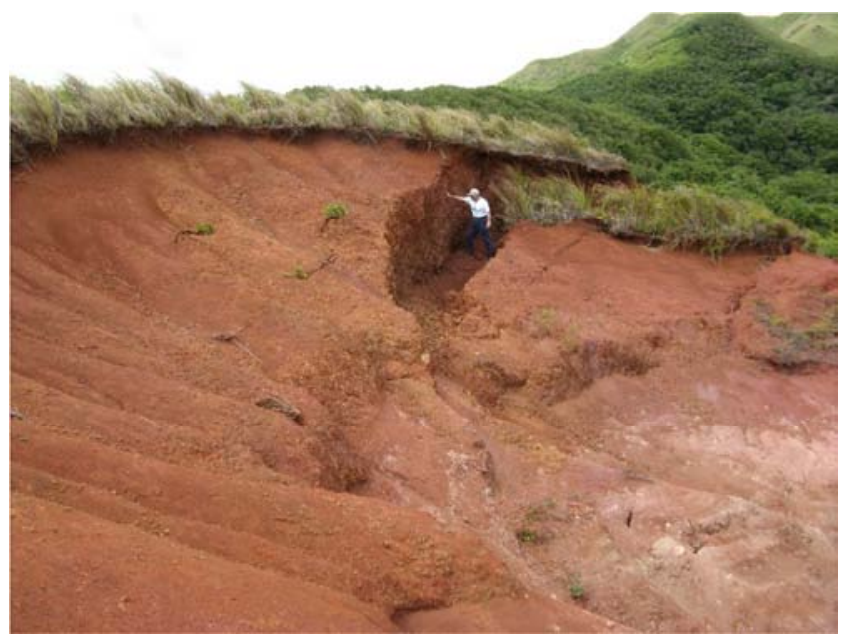

(a)

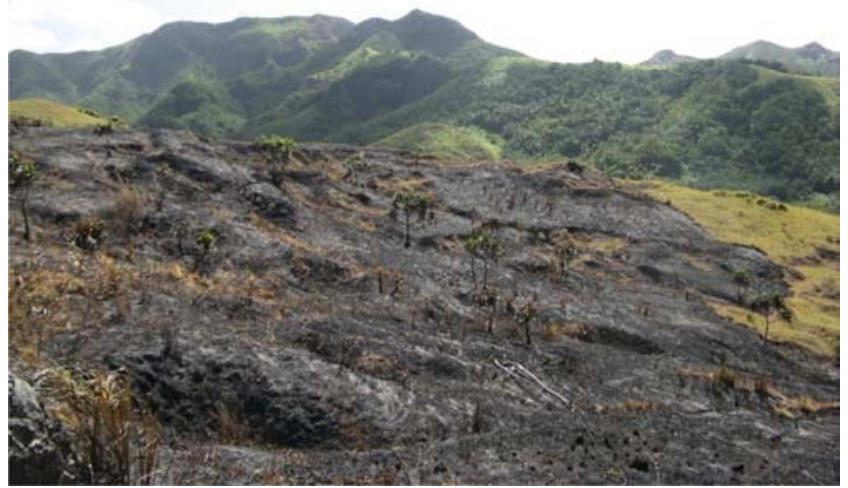

(b)

Figure 2. (a) Badlands atop the Pigua Ridge in Merizo, southern Guam; (b) Burned Savanna along the Geus Slopes in southern Guam.

\subsection{Hydrologic Data}

Hydrologic conditions were examined by quantifying rainfall, stream level, stream flow, and turbidity during dry and wet season conditions. The data were collected in the field with an array of instrumentation setup strategically within the watershed. In addition, manual field measurements were collected regularly during site visits for analyses and data quality evaluations. A primary hydrologic data collection station was set up at a selected location downstream from most of the major tributaries and $3 / 4$ of a mile inland from the coast (Figure 3). The Hydrologic data collection began on January 15, 2014 and data was collected through January 15, 2015.

Stream levels of the Geus River at the data collection site was measured using two HoboWare ${ }^{\circledR}$ U20 water level data loggers with a range of 0 to $30 \mathrm{ft}$ and an accuracy of $0.015 \mathrm{ft}$. (Figure 3). The level loggers were collocated with one level logger resting at the bottom of the water column and the other logger outside of the water column to account for atmospheric pressure variations. Pressure readings were collected at 5minute intervals, and the pressure difference between the river level logger and the atmosphere level logger provided the pressure (in psi) attributed to the water column.

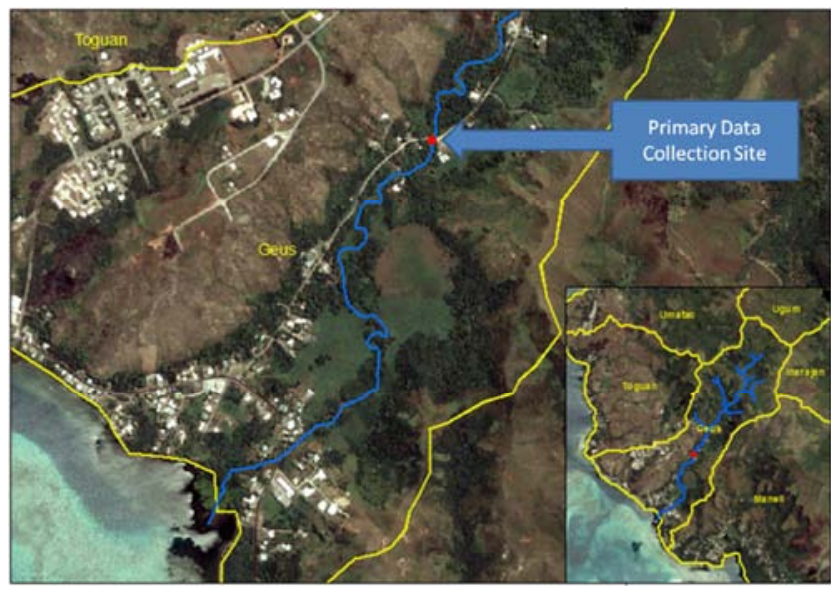

(a)

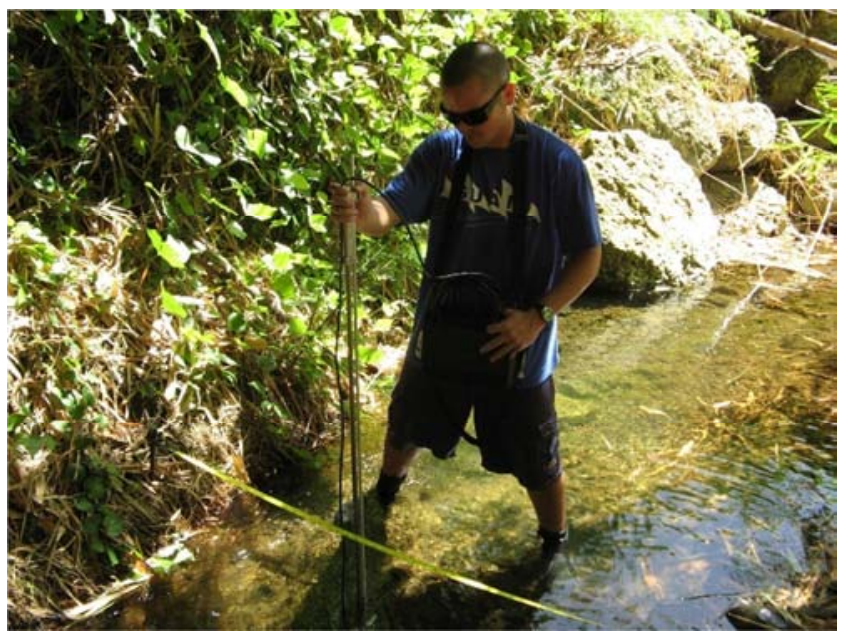

(b)

Figure 3. (a) Location of the hydrologic data collection station in the Geus River; (b) Stream flow measurement in the Geus River in southern Guam.

During data post-processing, a correction factor was applied to account for the actual location of the pressure sensor based on its orientation in the PVC housing and stream level baseline height established during dry season conditions. This was necessary to provide a more accurate stream level height and a consistent reference point for the stage discharge curve.

Stream flow was measured close to the primary data collection station during weekly site visits (Figure 3). A Flow-mate ${ }^{\mathrm{TM}}$ Model 2000 Portable Flowmeter was used to collect readings (in cfs) along a transect set perpendicular to flow direction. A correlation between total flow and stream level over time produces a discharge rating curve.

Turbidity was measured using a turbidity logger and a handheld turbidity meter. An Analite NEP495P Turbidity Logging Probe was installed to collect turbidity readings at 15-minute intervals in the water column. In addition, during 
weekly site visits water samples were collected and analyzed using an Omega TRH444 Portable Turbidity Meter. Both turbidimeters measures suspended particles in a solution based on the amount of light scatter produced with infrared light. Accuracy of the portable turbidity meter was verified prior to each use. The turbidity logger was calibrated prior to deployment and accuracy was assessed weekly by comparison with the portable turbidity meter. Maintenance was conducted weekly during long-term deployment and recalibration was conducted periodically as necessary.

Daily rainfall quantities were recorded by a rain gauge located on the Pigua ridge just upland from the primary data collection site. Toward the later part of the data collection period the Pigua rain gauge became faulty and no longer was supplying valid data. Therefore, supplemental rainfall data were also used from a rain gauge located in the Ugum Watershed (Figure 4). The rain gauges use two tipping buckets that collect water as it falls, recording each time the tipping buckets are activated representing a specific quantity of rainfall (0.01 in per tip).

Soil samples from seven locations were randomly selected and tested in the soil lab to identify the various soil types represented in the Geus Watershed (Figure 4). Samples were collected as composites from sample locations selected based on exposed soil observations or dominant vegetation types. Four samples were collected along the upland ridge including areas consisting of the more prominent Badlands and grasslands. Three samples were collected in the interior of the valley and along the River where more forest vegetation dominates.

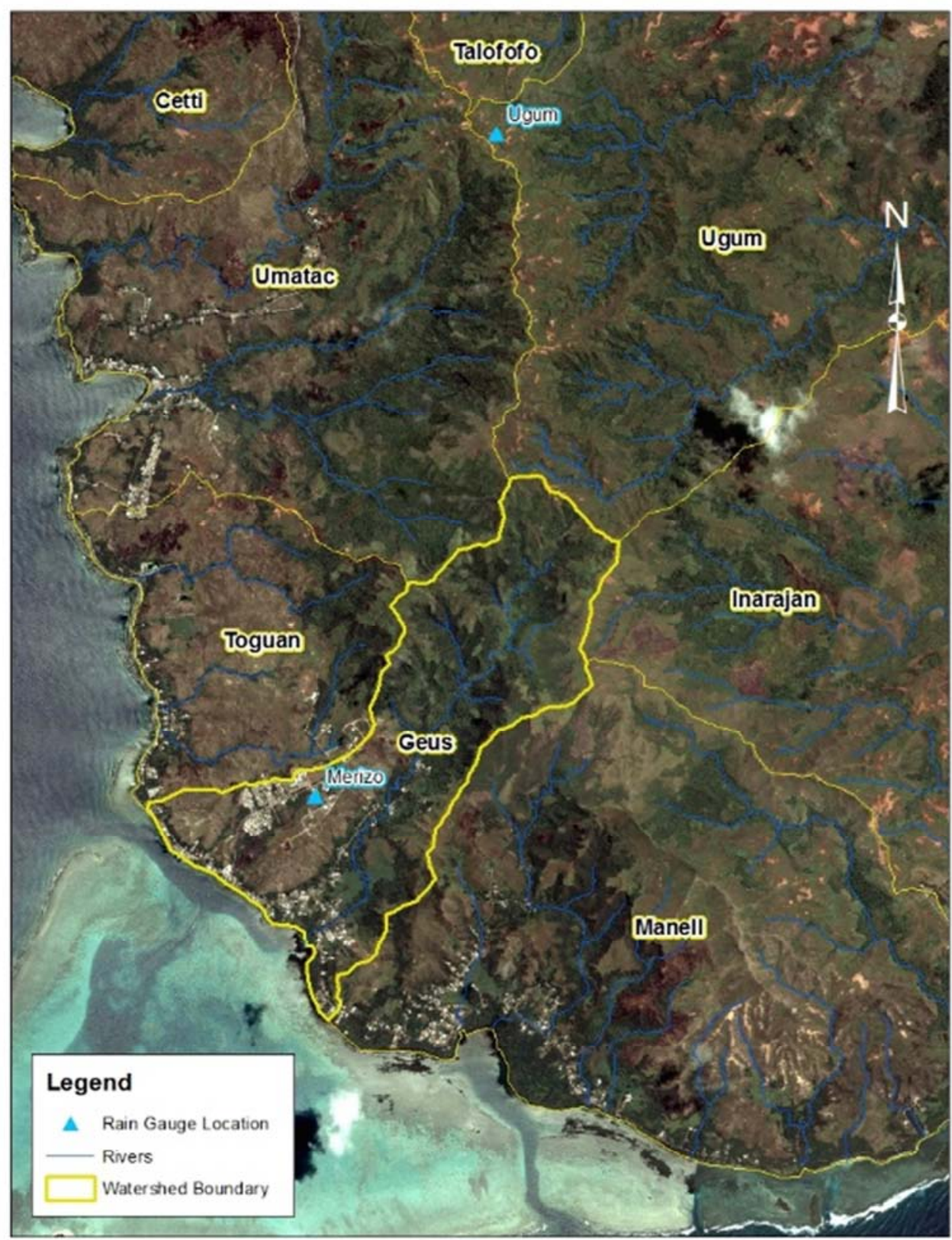

(a) 


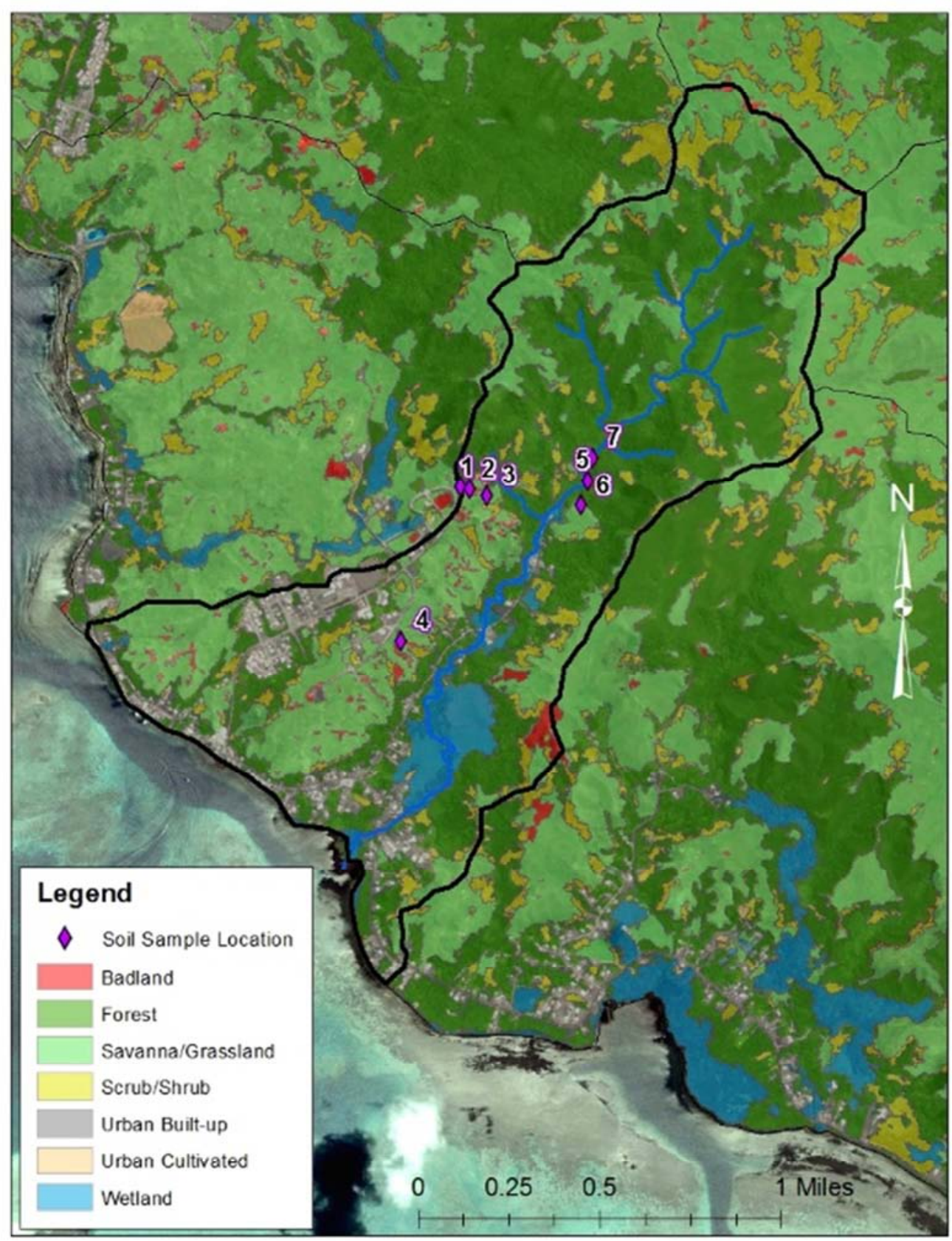

(b)

Figure 4. (a) Rain gauge locations in and around the Geus Watershed in southern Guam; (b) Soil sample locations within the Geus Watershed in Southern Guam.

Each composite sample consisted of five individual sample aliquots, collected to the depth of 12 in $(30 \mathrm{~cm})$ from the surface. Upon collection all samples were processed and analyzed at the University of Guam Soil Laboratory. Samples were dried, ground, then sifted through a standard two millimeter sieve. Sample aliquots were individually analyzed for $\mathrm{pH}$, soil texture, organic matter content, and nutrients. Soil $\mathrm{pH}$ was measured by using an electronic Oaktron $\mathrm{pH}$ meter.

The soil texture analysis was performed to determine sand, silt and clay content. In particular, a Bouyoucos hydrometer was used to find silt and clay content. Soil organic matter was determined by measuring the soil carbon using a rapid dichromate oxidation procedure known as the Walkley-Black Method [16]. Nutrients analyses were conducted via Spectronic meter for available phosphorus $(\mathrm{P})$, potassium $(\mathrm{K})$, calcium $(\mathrm{Ca})$, and Magnesium (Mg) using the Olsen method [17].

\subsection{GIS-RUSLE Model}

The GIS-based soil erosion model was applied to the Geus Watershed with the same data processing procedures as described by Park [18]. The R-factor, for the erosive power of rainfall, was digitized based on the isoerodent lines calculated by Dumaliang [19]. The K-factor, for soil-loss rate 
per erosion index unit, was taken as listed for each soil type in the Soil Survey of Guam [20]. The Geus Watershed soil types were obtained from the Digital Guam Atlas [21]. The L and $\mathrm{S}$ factors, for ratios of soil loss from field slope length and gradient, was calculated by the $\mathrm{C}++$ program based on a $1 \mathrm{~m}$ digital elevation model (DEM) [22].

The $\mathrm{C}$-factor, for land cover and management, was based on the 2011 landcover information provided in the Digital Guam Atlas [21] reclassified as was done by Park [18]. The P-factor, for soil loss with support practices, was assigned as 1 because there are no soil support practices currently taking place. The output of the GIS-based model was a color-coded map that differentiated areas that have a higher potential to contribute to soil erosion within the Geus Watershed.

\subsection{Aerial Survey}

Finally, an aerial photo survey was conducted in June 2014 using a custom built radio-controlled hexacopter equipped with a video camera. The main focus of the survey was general vegetation cover and the extent of the more critical high erosion areas within the Geus watershed. Limitations with this technology included shorter air time due to limited battery power, and narrower coverage and distance limits from the radio control. However, the lower elevation aerial footage allows for higher resolution photos.

\section{Results and Discussion}

\subsection{Hydraulic Data}

Over the course of the data collection period (from January 2014 to January 2015), rainfall, stream levels, stream flow, and turbidity showed the most variability from July through November.

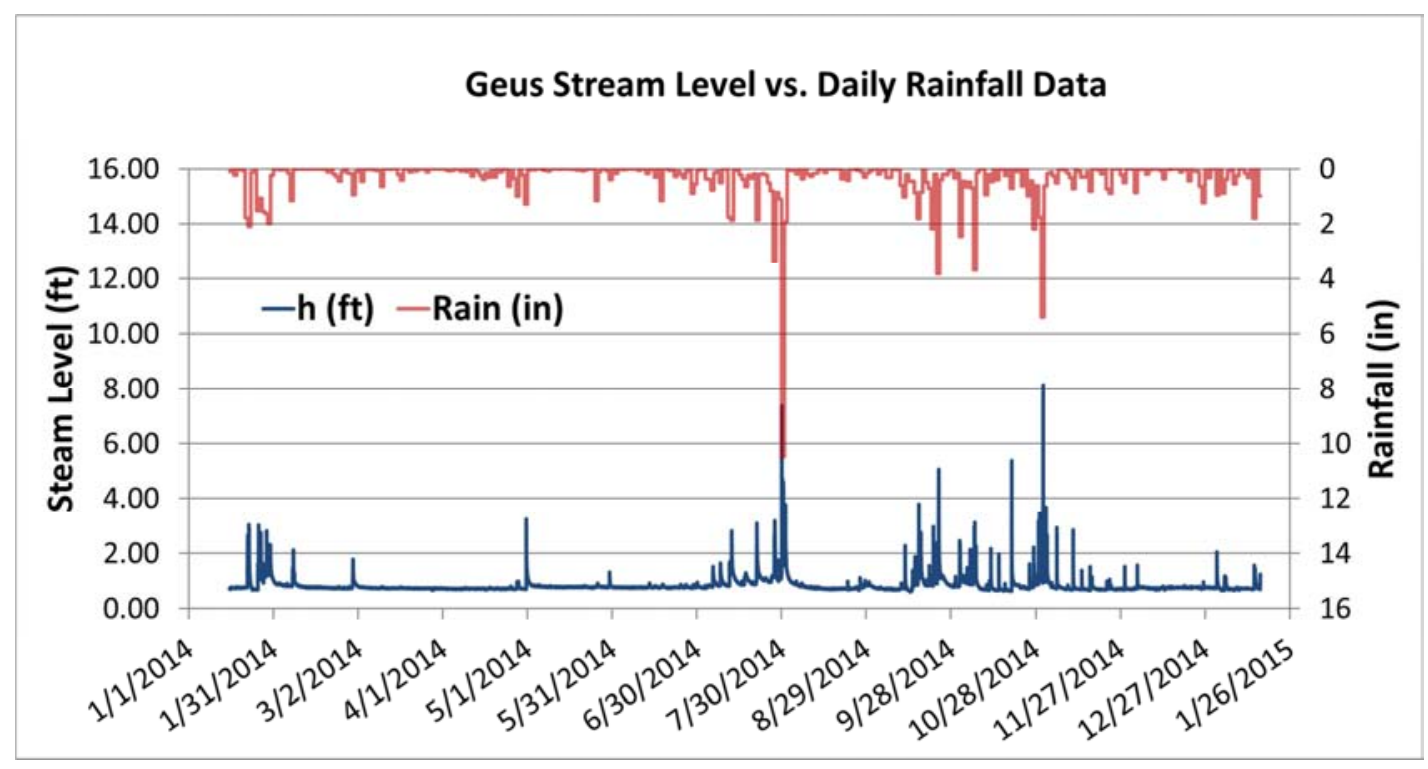

(a)

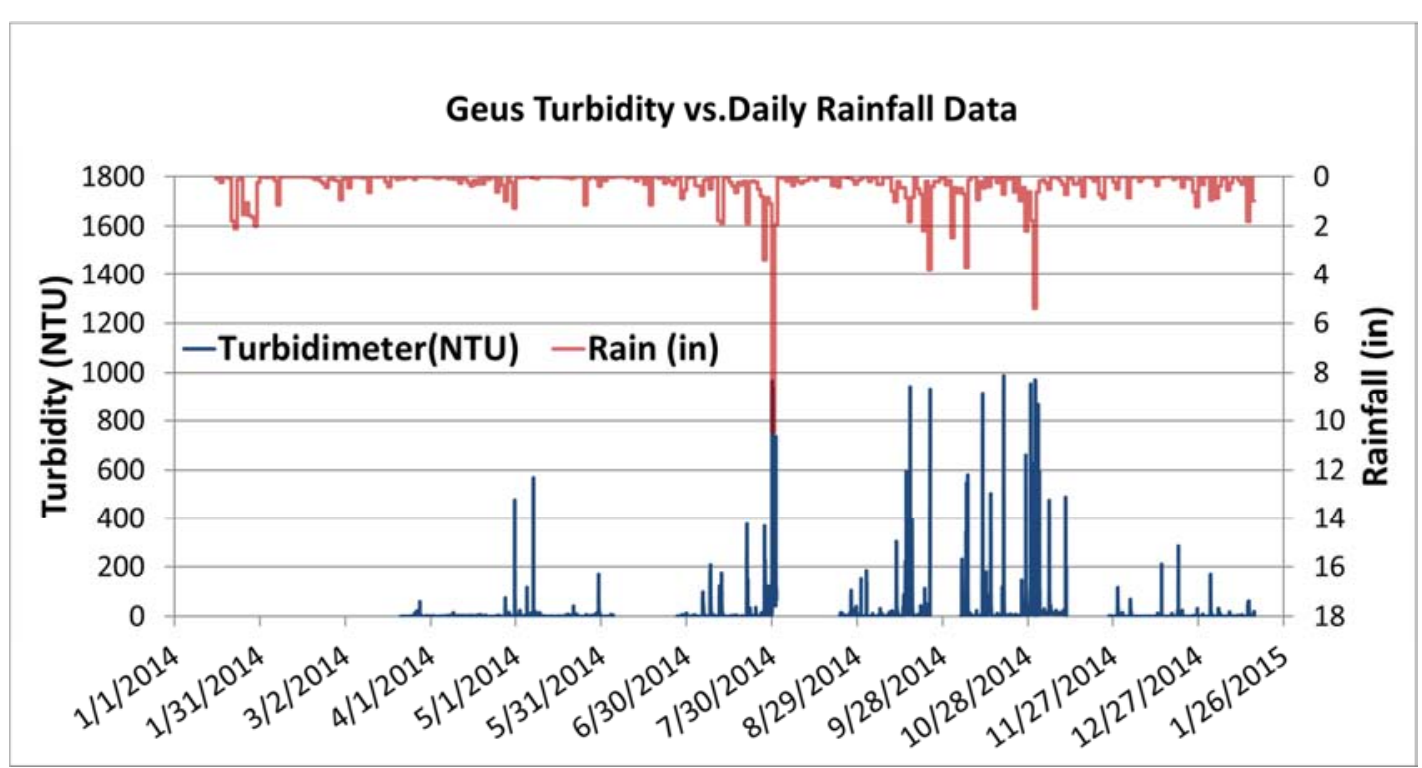

(b) 


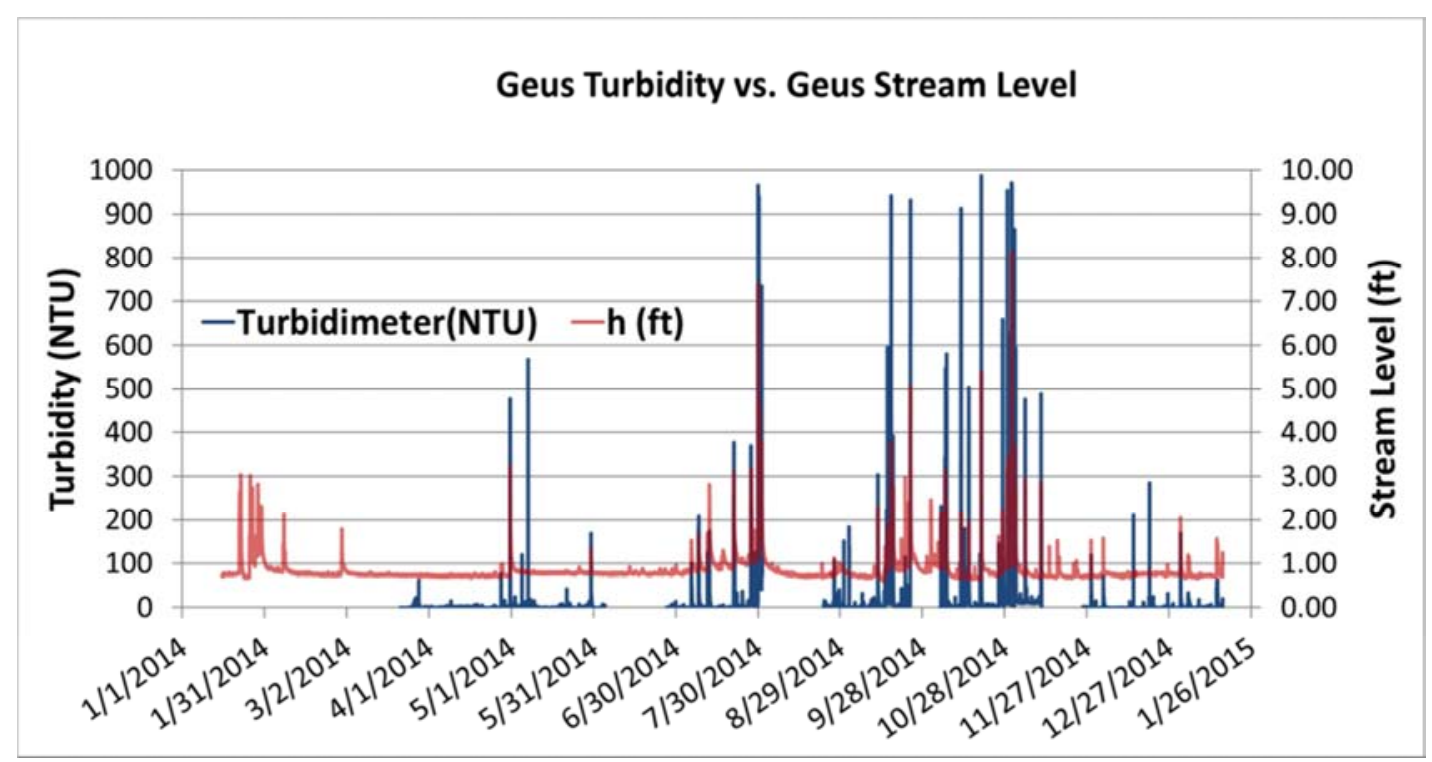

(c)

Figure 5. (a) 5-Minute stream level and daily rainfall totals; (b) 15-Minute turbidity readings and daily rainfall totals; (c) 15-Minute turbidity readings and 5minute stream level.

This was consistent with the typical rainy season period [15]. Based on the data, it appears there is a strong correlation between stream level and rainfall in the Geus Watershed (Figure 5a). In general, when daily rainfall averaged one to two inches, the stream level increased on the order of one to two feet. During heavier rain events, with daily totals reaching almost four to five inches, stream level showed significant spikes upwards of four to five feet depending on the intensity of the rainfall. There also appeared to be a strong correlation between turbidity in the Geus River and rainfall (Figure 5b). This observation is supported by overlaying stream level with stream turbidity measurements (Figure 5c). As a result, it was evident that the intensity of the storm was a key factor influencing erosion and runoff as indicated by levels of turbidity.

The dynamic response of the Geus watershed was also evident as rainy season storms produced high velocity flow events with maximum recorded turbidity readings. In fact, the largest rain event (Tropical Storm Halong) on July 30, 2014, caused so much sediment build-up around the turbidimeter that it affected the validity of the data until manual cleaning was completed. During this storm event the maximum stream level recorded was $7.0 \mathrm{ft}$ at 2:05 am, and the duration at that height was not longer than that 5-minute interval. During that spike, stream level was greater than $6 \mathrm{ft}$ for 30 minutes, greater than 5 $\mathrm{ft}$ for 40 minutes, and greater than $4 \mathrm{ft}$ for 70 minutes. Based on this data, the stream level doubled, then came back down (from 3.5 to $7 \mathrm{ft}$ ) in less than an hour and a half (Figure 6).

A similar pattern was exhibited in the turbidity data, which recorded a maximum concentration of 964.9 NTU from 2:15 am to 2:30 am (Figure 6). Turbidity above 900 NTUs lasted about an hour and a half, and significant increased were observed when stream level rose to greater than three feet. Routed rainfall data at a 15-minute delay correlated well with the 5-minute stream level data (Figure 6). The coefficient for rainfall routing best fits the stream level response with a delay of 15-20 minutes between peak rainfall and peak streak level. This storm event is one example that shows how dynamic the Geus Watershed is.

A time series during a period of storm activity in October 2014 also depicts the response time between rainfall, stream level, and turbidity (Figure 7). Based on the dimension of the Geus Watershed, the river floods appear to last less than a couple of hours. This shows that the dynamics of river runoff and suspended sediment fluctuated at a time scale of hours or less. Therefore, this is an important consideration in understanding the magnitude of sediment plumes versus the long-term erosion rate.

Based on the data collected, it was evident the intensity of the storm was a key factor influencing erosion and runoff as indicated by levels of turbidity. When rainfall occurs at higher intensities runoff contribution to the stream to increase up to a certain threshold, then turbidity begins to increase dramatically. This was observable during the worst conditions with the deployment of the turbidimeter which can log turbidity readings when it may otherwise be too dangerous for data collection at the time of the event (Figure 8). This information is important to understanding the baseline conditions of the watershed and helps to predict how the watershed may respond to future developments. 

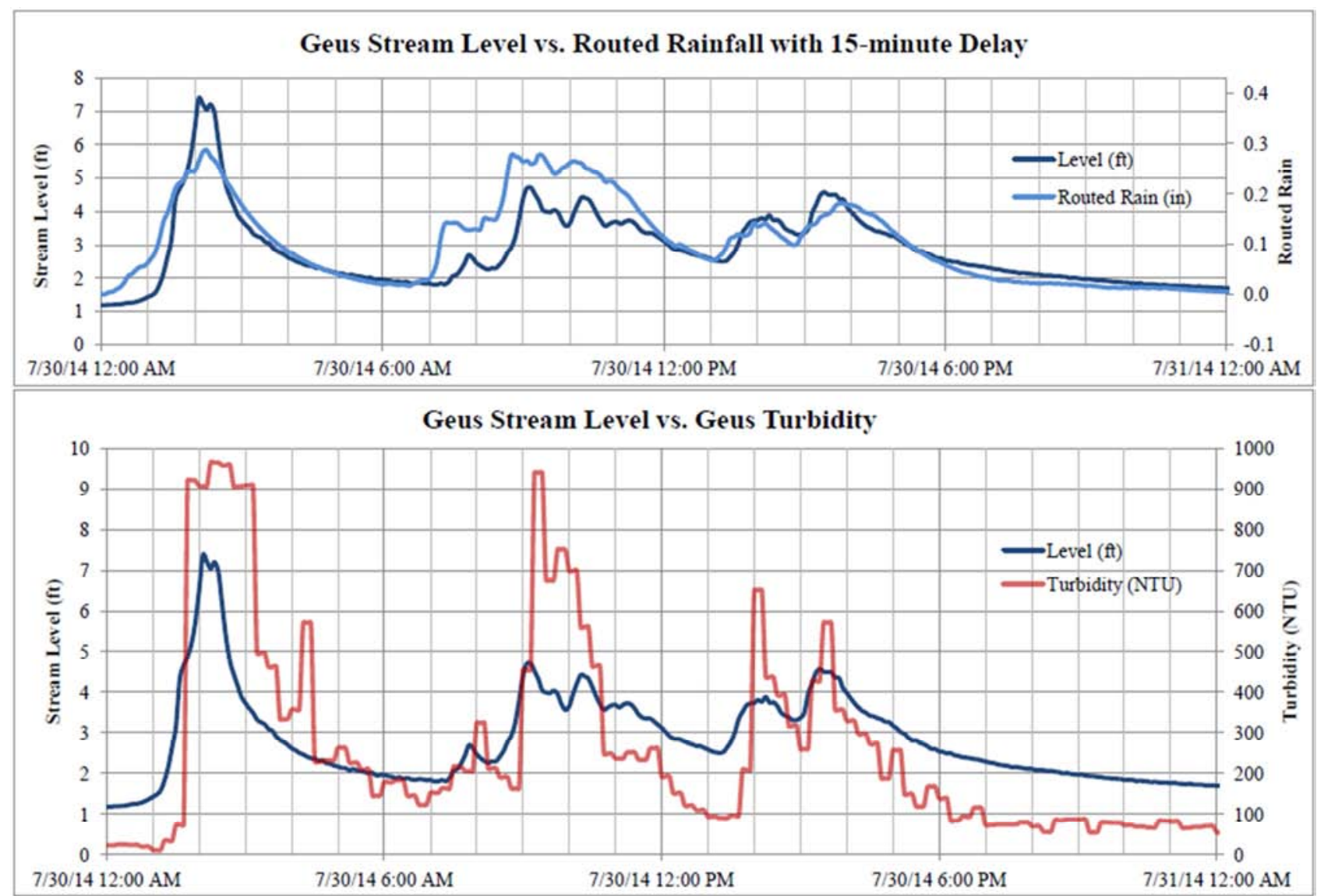

Figure 6. Routed rainfall \& 15-minute turbidity, versus 5-minute stream level data.

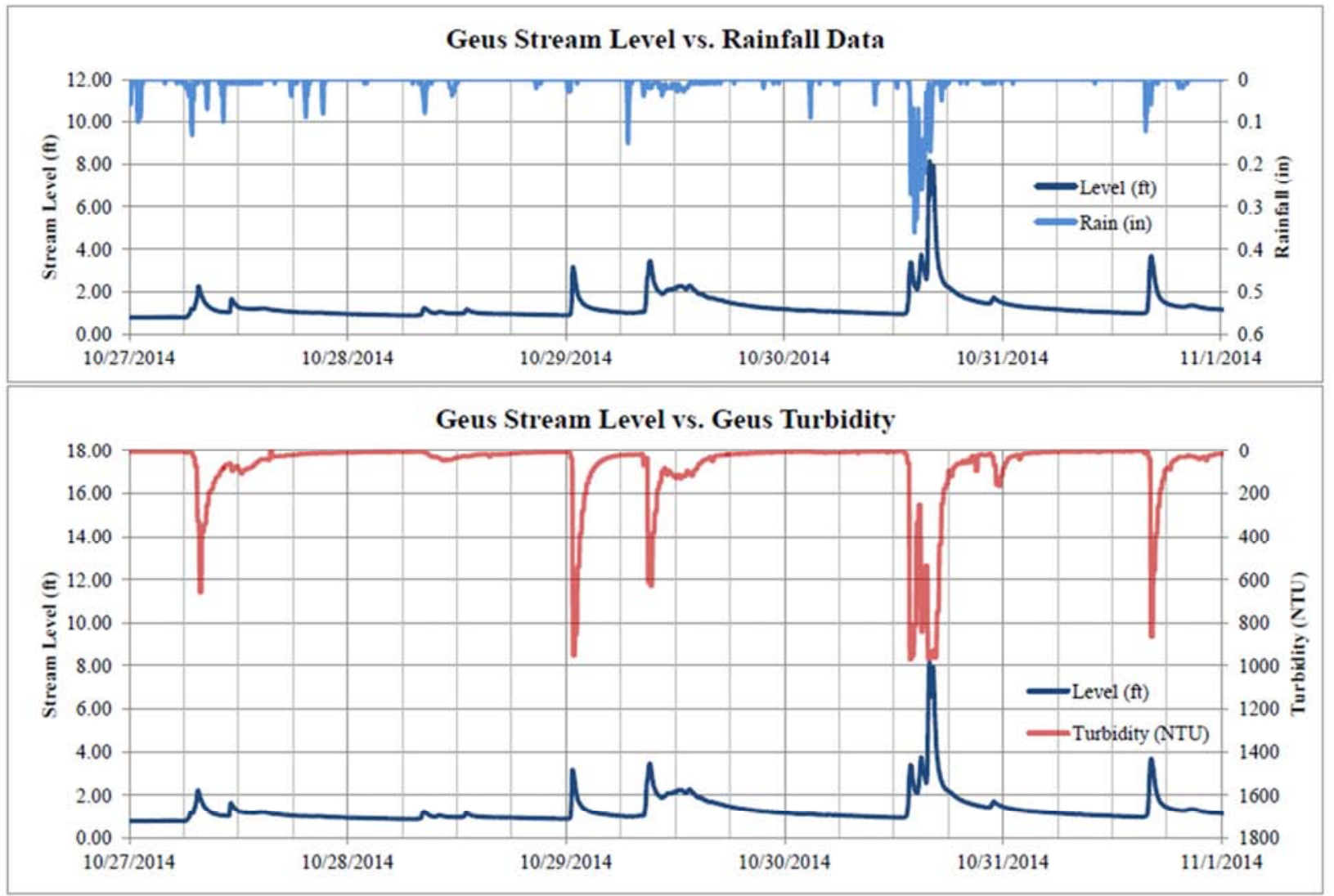

Figure 7. 5-minute rainfall \& 15-minute turbidity, versus 5-minute stream level data. 


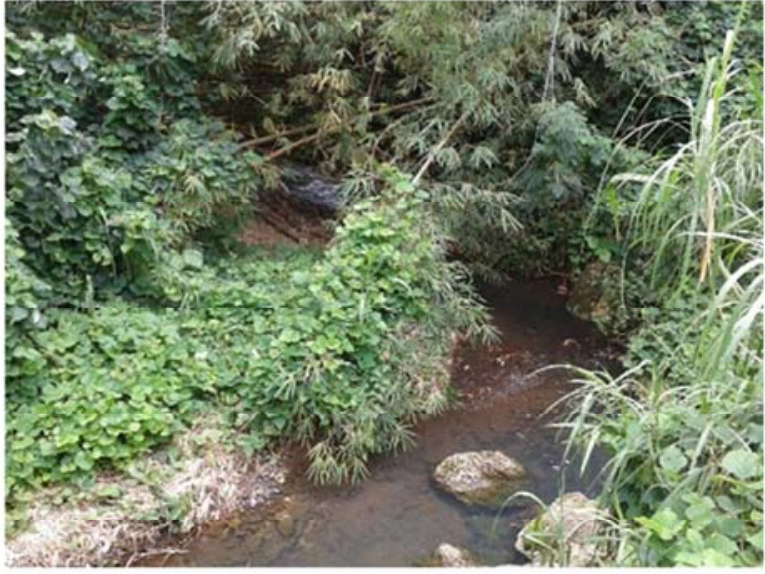

(a)

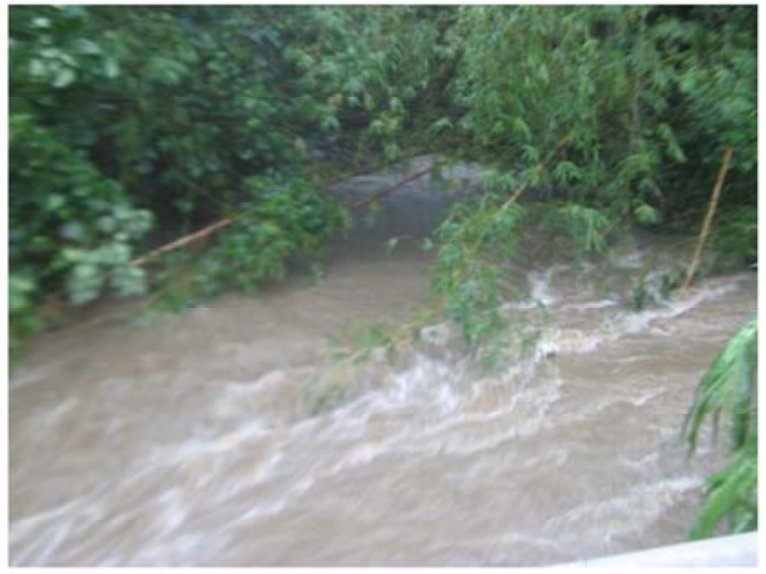

(b)

Figure 8. Geus River conditions (a) before and (b) during Tropical Storm Halong (July 18, 2014 and July 30, 2014, respectively).

\subsection{Development of Stage Discharge Curve for the Geus River}

The preliminary stage discharge curve is presented below (Figure 9). The stage discharge curve will gain greater accuracy as more data under a range of flow regimes continues to be collected over the course of several years or more.

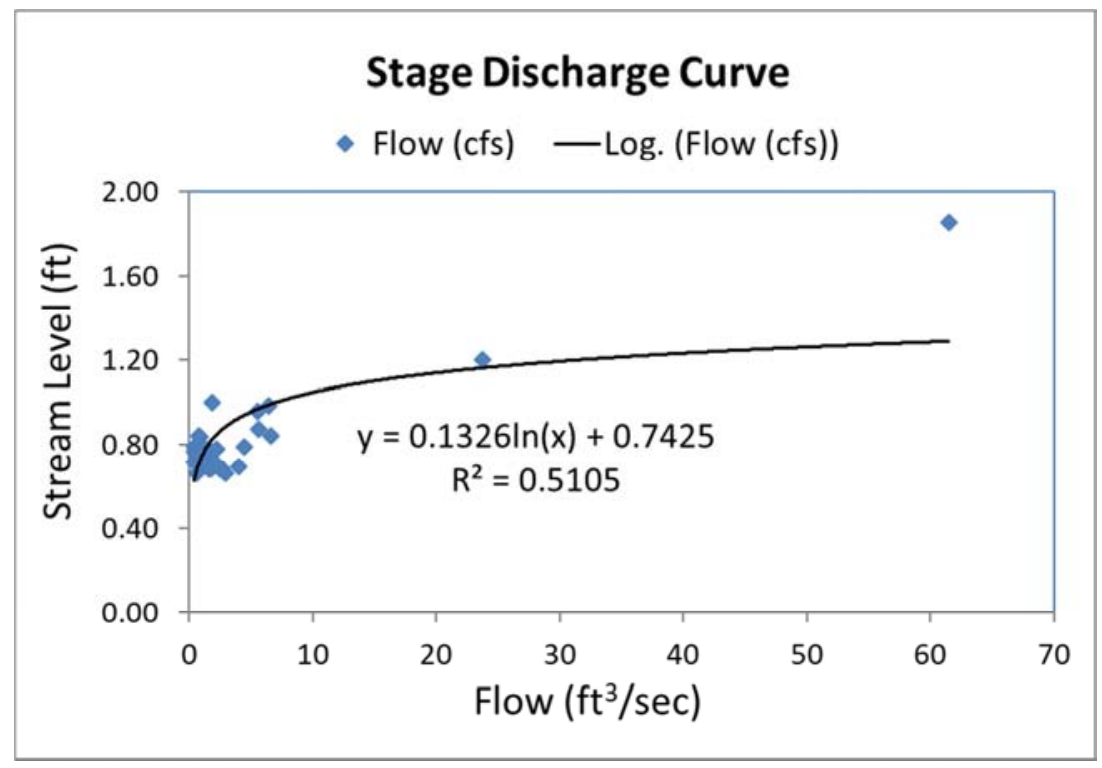

Figure 9. Preliminary Stage Discharge Curve for Geus River based on data collected.

This watershed management tool will provide an estimate of flow based on measured stream levels.

\subsection{Soil Sample Results}

Most soil $\mathrm{pH}$ ranges between 3.5 and 10.0. Soil $\mathrm{pH}$ is important because it has many effects, including influence on the availability of nutrients and toxicity in plants, and soil organism activities. Soil organic matter, such as plant, animal, microbial residue, and highly carbonized compounds such as coal, have important and potentially beneficial qualities. Organic compounds in soil may increase the holding capacity for plant nutrients and water, increase the cation exchange capacity, and lower bulk density. High organic matter in soil generally signifies sustainable fertility over the long-term. Available $\mathrm{P}$ has been typically just a fraction of total P. However, it is important because it represents the amount usable $\mathrm{P}$ in the system. The concentration of nutrients in general is an indicator of the ability of soil to support vegetation.

Soil sample results are presented in Table 1. Samples 1 and 2 were collected at some of the more extensive Badlands in the Geus Watershed. The low organic matter and lower levels of available nutrients suggests soils from this zone are very erodible. The lower levels of organic matter decrease the buffer effect provided by organic matter in soils and can correspond with lower $\mathrm{pH}$. Clayey soil texture means soil particles may not settle as quickly in the water column, heightening the effects of sedimentation. Samples 3 and 4 were also collected along the Geus Valley ridge where savanna-type vegetation dominates. 
Table 1. Soil sample results.

\begin{tabular}{llllllll}
\hline Sample & $\mathbf{p H}$ & $\mathbf{\%} \mathbf{~ O M}$ & Soil Texture & $\mathbf{K}(\mathbf{p p m})$ & $\mathbf{C a}(\mathbf{p p m})$ & $\mathbf{M g}(\mathbf{p p m})$ & $\mathbf{P}(\mathbf{p p m})$ \\
\hline 1 & 4.04 & 0.00 & Clayey & 44 & 787 & 691 & 0.56 \\
2 & 3.73 & 0.00 & Clayey & 105 & 373 & 4,617 & 0.11 \\
3 & 6.70 & 2.74 & Clayey & 82 & 12,389 & 2,585 & 1.15 \\
4 & 6.01 & 1.77 & Loam & 195 & 89,085 & 2,928 & 0.67 \\
5 & 6.17 & 2.58 & Sandy Clay Loam & 288 & 7,870 & 988 & 1.15 \\
6 & 5.66 & 6.12 & Clay Loam & 462 & 5,916 & 909 & 2.03 \\
7 & 6.37 & 5.15 & Sandy Clay Loam & 778 & 12,149 & 1,251 & 3.28 \\
\hline
\end{tabular}

There was slightly more organic matter and nutrients in the soil under vegetated conditions. However, the soil texture, little to moderate organic matter, and low P suggests the soil type that supports the savanna within the Geus Valley are unproductive hence, fairly susceptible to erosion. Samples 5, 6 , and 7 were collected along the central portion of the valley bottom. The vegetation supported by these soil types consisted mostly of ravine forest. In comparison to the samples collected along the ridge, the later samples showed higher organic matter, higher $\mathrm{pH}$, and more available nutrients in general These soils are likely less erodible.

Based on sample results from all the soil samples combined, $\mathrm{P}$ was considerably low and is possibly one of the limiting nutrients in the Geus Valley soils. Additionally, $\mathrm{Mg}$ was very high in all the samples, even up to toxicity levels. These results are signs that the Geus Watershed may not be suitable for agricultural uses unless it is heavily managed. Therefore, the native or existing vegetation is likely adapted to these conditions.

\subsection{GIS-RUSLE Model Results}

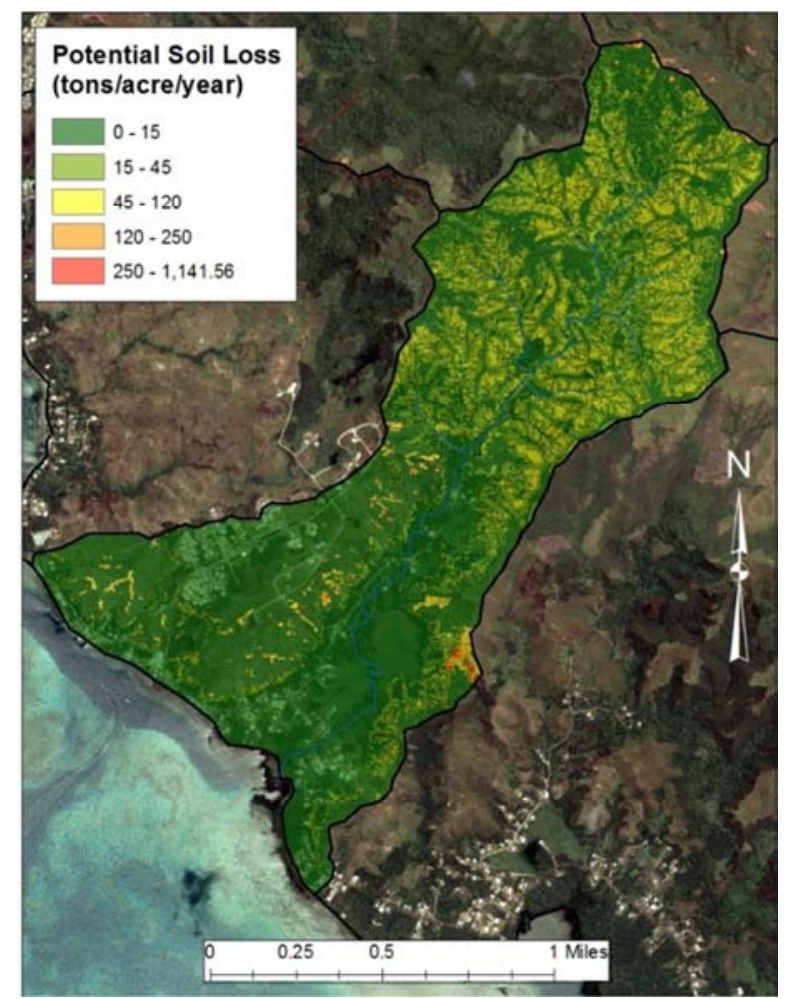

Figure 10. Results of GIS-Based Erosion Model showing areas within the Geus Watershed that have a higher contribution to erosion potential.
The results of the GIS-based erosion model are shown in Figure 10. Based on the results of the model, the mean annual rate of soil loss for the entire watershed is an estimated 16.78 tons/acre/year, with a standard deviation of 26.77 tons/acre/year.

The range of estimated annual soil erosion potential (maximum of 1,141.56 tons/acre/year) is considered an estimate that could be further evaluated based on empirical data. However, this data provides a general understanding of areas within the watershed that have the potential to contribute the most to soil erosion. The Badland locations along the ridges appear to be hotspots contributing the most to soil erosion (Figure 2). However, proximity to the river or its tributaries is an important factor in determining the likelihood that sedimentation can impact downstream communities. Therefore, the steep terrain at the back of the valley appears to also have some level of increased contribution to erosion based on this model.

\section{Recommendations for Watershed Management and Restorations}

The Geus Watershed has physical and geographical attributes characterized as having a relatively small catchment area, with steep valley walls carved out by rainfall over geologic time scales. In general, the Geus Watershed can be characterized by two separates but interacting regions, not relating to the way water flows (i.e., not in terms of subwatersheds): a northern (inland) region, and a southern (coastal) region.

The southern (coastal) half of the watershed bridges the land and the sea. It is easily accessible with roads that extend up the Pigua-side along the ridge, as well as at the base of the valley along the river. This region has a higher chance of human disturbance from fire, small-scale agriculture, and light residential developments. Due to frequency and the scale of the affected area, fire may be the most significant form of disturbance contributing to a higher erosion potential in this area.

Also, lower coastal region, the Geus River bottom has a less dramatic slope likely causing an accumulation of water and debris from upstream during heavy flow conditions. As a result, the stream channel here is more susceptible to flooding. In addition, the valley walls also have a more moderate slope. However, it supports heavily degraded 
savanna vegetation with patches of Badlands, especially along the Pigua Ridge. With decreased ground cover, sediment from surface erosion in these uplands can accumulate in small eroded channels and eventually into the River, having to travel a shorter distance to make it to the coast. Properties of soil in this region classify the soil as erodible.

Based on these characteristics, this area will not likely improve naturally, especially if it continues to burn periodically. It also will not benefit from any restoration or vegetative cover improvements unless public support to minimize the threat of fire can be achieved. The recommended options include outreach focused on the local community and more effective enforcement of Guam's laws against fugitive burning.

The northern (inland) half of the watershed is bound by the high peaks of the mountains. It is characterized by steep valley walls and deep channels eroded from heavy rain events causing fast-flow conditions. The back valley is more inaccessible and remains relatively undisturbed. The interior is dominated by ravine forests while stretches of savanna occupying the higher elevations. The savanna in this region appeared to be denser with more ground cover, likely affected by fire less frequently. Also, the interior valley vegetation is supported by more productive soil. Although it may burn less frequently, it would be more difficult to fight a fire in the back valley due to access limitations.

Based on these features, erosion from this region is associated more with the steepness of the terrain. Abundance of areas with greater erosion potential and proximity to the stream is a greater concern here. But the proximity to the ocean and the magnitude of erosion potential may be less detrimental to direct impacts along the coast.

Considering these findings, it is recommended that any future restoration activities be focused on the disturbed portions of the watershed. First of all, it seems logical that areas that are more directly impacted by human activities could be more effectively managed by human activities. Additionally, the ease of access which makes the area more susceptible to detrimental human actives also makes it more convenient for restoration.

This study did not include an analysis of efficiency of different management options. But, habitat restoration of the degraded savannas should be one of the goals. Since fire presents one of the most significant threats of disturbance, increased educational outreach and enforcement focused directly on the local community should help to ensure the longevity of restoration efforts. Now that baseline conditions have been determined, continued monitoring is recommended for evaluating the effectiveness of future restoration actions.

Along with presenting findings of baseline conditions, this study also alludes to aspects of the Geus Watershed that should be further investigated. For example, it is recommended that an additional monitoring station is installed upstream to quantify differences between the more easily accessible/developed regions of the watershed and the undisturbed regions. This will determine the extent of sedimentation that the north (inland) region of the watershed contributes downstream.

A similar, but more rigorous investigation can include monitoring stations in each of the major tributaries during rainy season. Finally, since one of the main goals of watershed management is the protection of Guam's nearshore reef ecosystems, an in-depth study to determine the quantity of sediment being discharged into the ocean from the Geus River should be conducted.

\section{Conclusions}

The hydrologic data collected shows that there is a rapid response to rainfall in the Geus River Watershed. The turbidity levels and stream flow increase with stream level during heavy rain events. Rainy season downpours can result in sediment plumes that travel downstream and can settle, accumulating in near-shore reef communities making the habitat increasingly unsustainable. Analyses of field data show a strong correlation between stream level, turbidity, and rainfall within the watershed, suggesting a highly dynamic nature of Geus watershed. Field data was used to create a stage discharge curve which will increase the efficiency of future watershed management by providing an estimate of stream flow from a simple measure of water level.

To support the hydrologic data collected, field visits, aerial surveys, and GIS-erosion models were conducted to provide a more qualitative understanding of watershed attributes that may contribute to erosion. Results of soil samples and a GISbased erosion model shows erosion potential "hotspots." It is also suggested that Fire and disturbed savanna, with intermixed Badland complex are biggest threat to increased upland erosion. Testing of soil samples suggest that highly erodible areas can be best managed with vegetation suitable for watershed conditions. Finally, continued and increased monitoring along with increased community outreach and enforcement is recommended for effective sustainable watershed management and restoration.

\section{Acknowledgements}

This study was funded by the National Oceanic and Atmospheric Administration (NOAA) through the University of Guam Water and Environmental Research Institute (WERI) via the Guam Bureau of Statistics and Plans, Guam Coastal Management Program (Government of Guam Project No. NA11N054820007).

\section{References}

[1] Minton D. Fire, Erosion, and Sedimentation in the Asan-Piti Watershed and War in the Pacific NHP, Guam. Technical Report 150, Pacific Cooperative Studies Unit, University of Hawaii at Manoa. November 2006. 
[2] Khosrowpanah Sh, Lander M, Golabi M, and Manibusan S. A GIS-Based Watershed Management Plan for the Piti-Asan Watersheds. Technical Report No. 139, Water and Environmental Research Institute, University of Guam. October 2012.

[3] Khosrowpanah Sh, and Jenson J. Environmental Assessment for Non-Point Sources of Pollution for Ugum Watershed. Technical Report No. 109, Water and Environmental Research Institute, University of Guam. December 2005.

[4] Wolanski, ER, Richmond H, Davis G, and Bonito V. 2003a. Water and fine sediment dynamics in transient river plumes in a small, reef fringed bay, Guam. Estuarine Coastal and Shelf Science 56: 1-13.

[5] Burdick D, Brown V, Asher J, Gawel M, Goldman L, Hall A, Kenyon J, Leberer T, Lundblad E, McIlwain J, Miller J, Minton D, Nadon M, Pioppi N, Raymundo L, Richards B, Schroeder R, Schupp P, Smith E, and Zgliczynski B. 2008 The State of Coral Reef Ecosystems of Guam. Waddell, JE and AM Clarke, editors. 465-509.

[6] Dumaliang P, and Khosrowpanah S. 1998. Soil Erosion in Micronesia. American Water Resources Association: Third International Symposium on Tropical Hydrology and Fifth Caribbean Islands Water Resources Congress, San Juan, Puerto Rico. July 12 - 16, 1998.

[7] Lewis RR. 1999. MA thesis on Quantifying Geomorphic Processes of Guam's Taelayag River Badlands by Determining Rates of Basin Yield, Slope Retreat and Fracture Movement. University of Guam. Mangilao, Guam. December 1999.

[8] Scheman, NS, Khosrowpanah S, Golabi MH, and Heitz L. 2002. Identification of Erosion Processes and Sources of Exposed Patches in the La Sa Fua Watershed of Southern Guam. Technical Report No. 99, Water and Energy Research Institute, University of Guam. December 2002.

[9] Golabi, MH., C. Iyekar, and M. J. Denney. 2005a. Challenges and Actions Regarding the Rehabilitation of Degraded Lands: Case Study from the Pacific Island of Guam. Sociedade \& Natureza, Uberlandia, Special Issue, 87-106. May 2009.

[10] Park MH. 2007. M. S. thesis on Developing a GIS-Based Soil Erosion Potential Model for the Ugum Watershed. University of Guam. Mangilao, Guam.

[11] Forestry and Soil Resources Division (FSRD). 2010. Guam Statewide Forest Resource Assessment and Resource Strategy 2010-2015. Department of Agriculture. Prepared by Watershed Professionals Network (WPN).
[12] Manibusan S. 2012. MA thesis on The Hydrologic Response of the Piti-Asan Watershed to Development. University of Guam. Mangilao, Guam. October 2012.

[13] UNCCD. (2017). The Global Land Outlook (GLO) Report by UNCCD. First Edition: https://global-landoutlook.squarespace.com/the-outlook/\#the-bokk. United Nations Convention to Combat Desertification.

[14] Khosrowpanah Sh, Heitz L, Wen Y, and Park M. 2007a. Developing a GIS-Based Soil Erosion Potential Model of the Ugum Watershed. Technical Report No. 117, Water and Environmental Research Institute, University of Guam. December 2007.

[15] Lander MA, and Guard, CP. 2003. Creation of a 50-Year Rainfall Database, Annual Rainfall Climatology, and Annual Rainfall Distribution Map for Guam.

[16] Schumacher BA. 2002. Methods for the Determination of Total Organic Carbon (TOC) in Soils and Sediments. Ecological Risk Assessment Support Center, Office of Research and Development. US Environmental Protection Agency. NCEA-C-1281, EMASC-001. April.

[17] Olsen SR, Cole CV, Watanabe FS, and Dean LA. 1954. Estimation of available phosphorus in soil by extraction with sodium bicarbonate. U.S. Department of Agriculture. Circ. 939.

[18] Park MH. 2007. M. S. thesis on Developing a GIS-Based Soil Erosion Potential Model for the Ugum Watershed. University of Guam. Mangilao, Guam.

[19] Dumaliang P. 1998. M. S. thesis on The Determination of RFactors for Southern Guam by accounting for Climate Variability. University of Guam. Mangilao, Guam. March 1998.

[20] Young FJ. 1988. A Soil Survey of the Territory of Guam. Soil Conservation Service, United States Department of Agriculture (USDA).

[21] Khosrowpanah Sh, Wen Y, and Heitz L. 2007b. Development of a digital watershed atlas for Guam. Technical Report No. 116, Water and Environmental Research Institute of the Western Pacific, University of Guam. 2007.

[22] Van Remortel RRM, and Hickey R. 2004. Computing the RUSLE LS Factor based on Array-based Slope Length Processing of Digital Elevation Data Using a C++ Executable. Computers and Geosciences Volume 30. No. 9-10, pgs 1,0431,053 . 